\title{
Effectiveness of Ultrasonography Guided Femoral Nerve Block for Patient Positioning during Central Neuraxial Block in Elderly Patients for Fracture of Femur - A Prospective, Randomized Control Trial
}

\author{
Ratindra Kumar Barman¹, Karamchand Basumatary², Ananta Hazarika³
}

1, 2, 3 Department of Anaesthesiolgy, Tezpur Medical College \& Hospital, Tezpur, Assam, India.

\section{ABSTRACT}

\section{BACKGROUND}

Central neuraxial blocks, mainly spinal anaesthesia is the preferred anaesthesia over general anaesthesia in fracture of femur surgeries in elderly patients because of various side effects associated with general anaesthesia. However, the majority of the patients during positioning for spinal anaesthesia are associated with severe pain for which positioning becomes difficult. We wanted to assess the effectiveness of ultrasound (USG) guided femoral nerve block (FNB) to reduce pain during the positioning for spinal anaesthesia in fracture femur patients.

\section{METHODS}

It was a randomized control trial conducted on 80 elderly ASA I, II and III patients ( 45 - 70 years) posted for various femur surgeries under spinal anaesthesia having visual analogue scale (VAS) $\geq 4$ during positioning. Patients in group FNB $(\mathrm{N}=40)$ received USG guided femoral nerve block with $0.2 \%$ ropivacaine and in control group $(\mathrm{N}=40)$ didn't receive any interventions preoperatively. All patients received injection fentanyl during positioning if VAS $\geq 4$. Parameters recorded included VAS at baseline, 15 mins and during positioning, anaesthesiologist's satisfaction (yes or no), total fentanyl consumption and patient's satisfaction (Likert scale).

\section{RESULTS}

Demographic variables were comparable to each group. VAS in FNB at 15 mins and during positioning was $2.3 \pm 1.042$ and $3.025 \pm 0.831$ in comparison to $6.125 \pm 0.607$ and $7.2 \pm 0.822$ in control group respectively. Only 5 patients required injection fentanyl and total consumption was $142 \pm 3.21 \mu \mathrm{g}$ in FNB group while all patients in control group required injection fentanyl and total consumption was $1162 \pm 4.43 \mu \mathrm{g}$. Anaesthesiologists and patients satisfaction were much higher in FNB group.

\section{CONCLUSIONS}

USG - guided FNB is very effective in controlling pain during positioning for spinal anaesthesia in fracture femur patients.

\section{KEY WORDS}

Ultrasound, Femoral Nerve Block, Spinal Anaesthesia, Ropivacaine, Fracture Femur
Corresponding Author: Dr. Karamchand Basumatary, Department of Anaesthesiolgy, Tezpur Medical College, Bihaguri, Sonitpur - 784010, Assam, India.

E-mail: basu.karam@gmail.com

DOI: $10.14260 /$ jemds/2021/490

How to Cite This Article:

Barman RK, Basumatary K, Hazarika A. Effectiveness of Ultrasonography guided femoral nerve block for patient positioning during central neuraxial block in elderly patients for fracture of femur - a randomized control trial. J Evolution Med Dent Sci 2021;10(31):2390-2395, DOI: $10.14260 / \mathrm{jemds} / 2021 / 490$

Submission 01-02-2021, Peer Review 02-06-2021, Acceptance 08-06-2021, Published 02-08-2021.

Copyright (C) 2021 Ratindra Kumar Barman et al. This is an open access article distributed under Creative Commons Attribution License [Attribution 4.0 International (CC BY 4.0)] 


\section{BACKGROUND}

Fracture of the femur such as fracture shaft of femur, trochanteric fracture or fracture neck of femur are a common orthopaedic problems in the geriatric age group following trivial trauma, although fracture shaft of the femur is more common in young adults following a major accident. ${ }^{1}$ It is a painful bone injury and early surgical repair is the treatment of choice. Surgical repair comprises of either replacement of femoral head or internal fixation of the fracture. Dynamic hip screw, intramedullary nailing or plating of the femoral shaft are the common procedures performed in these types of fracture.2,3 Patients with the fracture of femur present special problems to the anaesthesiologists. Both general and central neuraxial anaestheisa can be used. In general, central neuraxial blocks, mainly spinal anaesthesia are preferred over general anaesthesia for all orthopaedic surgeries of lower extremities as it is easier and avoiding airway manipulations, thus have better respiratory and haemodynamic stability. ${ }^{4-8}$ Early mobilization and better postoperative analgesia lead to lesser chance of deep vein thrombosis and lesser hospital stay. Despite having so many advantages, at times it is very difficult to perform spinal anaesthesia due to poor positioning secondary to pain.

Generally, the technique of spinal anaesthesia is performed in sitting position in fracture femur patients. Patient positioning for spinal block is a pragmatic issue because of the extreme pain associated with limb movement. 9 Correct positioning during spinal block is the prerequisite in order to perform spinal anaesthesia successfully. The failure to effectively control the pain before surgery in femur fracture patients may lead to potential risks of cardiovascular events due to increased sympathetic stimulation associated with pain, particularly in elderly patients with co-morbidities. Various modalities of analgesia have been utilized for positioning which include opioids, midazolam, ketamine, nonsteroidal anti-inflammatory drugs and regional blocks such as fascia iliaca block and femoral nerve block (FNB). ${ }^{10}$ The use of opioids and different sedative agents may cause severe respiratory depression, particularly in co-morbid conditions. Femoral nerve block features as a rescue analgesia so as to provide adequate analgesia for facilitation of satisfactory positioning for neuraxial block. ${ }^{11}$ Femoral nerve block is an easy and safe block to perform owing to the easily identifiable landmarks and also because the nerve is usually superficial.

Ultrasonography (USG) using linear probe is an useful tool in identifying the femoral vessels and nerves which are closely related to each other and thus helps in avoiding inadvertent vessel puncture during femoral nerve block. Karmakar (2017) and his team compared analgesic effect of two different dosages of local anesthetic (LA) solution administered for USG - guided FNB given to facilitate optimal positioning for conduct of central neuraxial block. Study demonstrated that USG guided FNB with $12 \mathrm{ml}$ of LA solution was as effective as $15 \mathrm{ml}$ of LA solution for achieving adequate pain relief so as to give optimal positioning for central neuraxial block in patients of fracture neck of femur. ${ }^{11}$ Our study was an attempt to evaluate the effectiveness of single dose USG - guided femoral nerve block for patient positioning before and during spinal anaesthesia procedure in elderly patients with fracture femur with regard to better patient and anaesthesiologist satisfaction.

\section{METHODS}

The study was conducted in orthopaedic operation theatre of Tezpur Medical College and Hospital, Tezpur, Assam, after receiving approval from the institutional and ethical committee. It was a randomized control trial conducted from September 2019 to August 2020. American Society of Anaesthesiologists (ASA) I, II and III physical status patients posted for various elective surgeries of the femur were included in the study.

\section{Sample Size Determination}

The sample size required for this study was estimated from our findings in 20 pilot patients. Our pilot study had demonstrated that patients given FNB had lower pain scores (mean $=2.7$ ) during positioning. Based on $\alpha=0.05, \beta=0.20$ and a mean difference of 2.6 in pain score, with an estimated standard deviation of 3.9 , a sample size of 36 per group was required. Considering a dropout of $10 \%, 40$ patients in each group and a total of 80 patients were included in this study.

\section{Inclusion Criteria}

- $\quad$ Age 45 - 75 years.

- $\quad$ ASA physical status I, II and III.

- $\quad$ Scheduled for elective femur fracture surgeries.

- $\quad$ Having pain $(V A S \geq 4$ ) at rest and during positioning.

\section{Exclusion Criteria}

- No pain during sitting

- Patient refusal

- Presence of coagulation disorders

- Presence of multiple fractures

- Patient with head injury or other injuries

- Presence of peripheral neuropathy

- Patients with allergy to local anaesthetic solutions

- Patients with sepsis

- Skin lesions or infection at the site of FNB injection

\section{Randomization}

It was done with stratified randomization along with computer assisted randomization with research randomizer website. 40 randomized patients received FNB 15 mins (FNB group) before spinal anaesthesia while 40 patients were not given FNB in the control group.

All patients were subjected to routine preoperative assessment and fasting protocols. All patients were visited in the night before surgery and explained about the anaesthetic procedure and the outcomes. Written and informed consents were taken. All patients received oral alprazolam $0.5 \mathrm{mg}$ and injection pantoprazole $40 \mathrm{mg}$ in the night before surgery and in the morning on the day of surgery. All participants were 
explained about the visual analogue score (VAS) during the pre- anaesthetic visit. Patients were given a VAS scale containing a straight line with numbers from 0 to 10 equidistant to each other and asked to encircle the number according to their pains. 0 means no pain and a score of 10 means a worst possible pain.

In the operation theatre, intravenous infusion line was secured and standard monitoring devices measuring noninvasive blood pressure (NIBP), Pulse Rate (PR), percentage oxygen saturation $\left(\mathrm{SPO}_{2}\right)$ and Continuous Electrocardiography (ECG) were attached and baseline recordings were taken. Baseline heart rate, mean arterial pressure were recorded and thereafter at 15 mins and during positioning were recorded. All patients were preloaded with ringer lactate $10 \mathrm{ml} / \mathrm{kg}$ in the preoperative area.

The severity of pain was assessed with the help of VAS as a baseline pain score. A single experienced operator performed USG - guided FNB with $15 \mathrm{ml} 0.2 \%$ ropivacaine in the FNB group. Patients in the control group did not receive any interventions. The blocks were performed in an in-plane technique using linear array probe under realtime visualization in USG and also after eliciting a motor response using a peripheral nerve stimulator (Stimuplex ${ }^{\circledR}$; B Braun, Melsungen, AG, Germany).

The injection was carried out from the lateral to the medial side after visualizing the nerve just lateral to the femoral artery. Drug was injected after eliciting quadriceps contraction at stimulating current of $0.3-0.5 \mathrm{Ma}$. Ultrasound machine used during the study was ECHO - SON S.A. The relief of pain following FNB was assessed quantitatively using the VAS 0 no pain to 10 - worst pain) at baseline, at 15 mins and during positioning.

All neuraxial blocks were performed in the sitting position by an anesthesiologist who was blinded for the study. Time required for spinal block was recorded. Anesthesiologist's satisfaction with patient positioning maintained for the spinal block (yes = satisfactory, no = not satisfactory) were also recorded. Patient's satisfaction was assessed according to the 5 points Likert scale chart. ${ }^{12}$ Patients were asked if femoral nerve block reduced the pain of fracture during positioning. Scores were recorded as - Strongly disagree - 1, Disagree - 2, Neither agree nor disagree -3 , Agree -4 , Strongly agree -5 .

If any patient complained of VAS $\geq 4$ during positioning, IV fentanyl 0.5 microgram $(\mu \mathrm{g})$ per kilogram $(\mathrm{kg})$ of body weight was given every 5 min until the pain score decreased to VAS < 4. Assessors of pain were blinded to the patients' allocated treatment group and remained outside the operating room during the administration of FNB. Thereafter, they came into the operating room to assess the pain score.

\section{Statistical Analysis}

Quantitative variables were described as mean \pm SD; qualitative variables were described as numbers (percentage). For parametric data analysis, independent sample $\mathrm{t}$ - test was used between the two groups. A paired sample $t$-test was used between the same groups in different time intervals. For nonparametric data analysis, chi-square test for nominal scale and Mann - Whitney U test were used. A P - value $<0.05$ was considered to be statistically significant.

\section{RESULTS}

Data, presented as mean \pm standard deviation or numbers of patients (\%) were tabulated and analyzed in Microsoft Excel 7. 80 patients were enrolled in our study.(Figure1) Demographic data and baseline heart rate (HR), mean arterial pressure (MAP) presented as Mean \pm SD are comparable in each group (Table 1 and Figure2 ).

\begin{tabular}{|c|c|c|c|c|}
\hline & Variable & $\begin{array}{c}\text { FNB Gr } \\
\text { Mean } \pm \text { SD }\end{array}$ & $\begin{array}{l}\text { Control Gr } \\
\text { Mean } \pm \text { SD }\end{array}$ & P - Value \\
\hline & Age & $58.45 \pm 12.2$ & $57.075 \pm 12.61$ & 0.6 \\
\hline \multirow{8}{*}{ Sex } & Female (\%) & $19(47.5 \%)$ & $20(50 \%)$ & 0.62 \\
\hline & Male (\%) & $21(52.5 \%)$ & $20(50 \%)$ & 0.58 \\
\hline & Height & $164.078 \pm 4.9$ & $158.65 \pm 4.2$ & 0.32 \\
\hline & Weight & $58.45 \pm 12.2$ & $58 \pm 8.7$ & 0.47 \\
\hline & \multicolumn{3}{|c|}{ ASA status } & \\
\hline & ASA I & $8(20 \%)$ & $10(25 \%)$ & \\
\hline & ASA II & $20(50 \%)$ & $20(50 \%)$ & \\
\hline & ASAIII & $12(30 \%)$ & $10(25 \%)$ & \\
\hline \multicolumn{5}{|c|}{ Table 1. Demographic Data } \\
\hline
\end{tabular}

Baseline heart rate (HR) in FNB group and control groups were $97 \pm 5.55$ and $96.4 \pm 6.54$ respectively and were comparable to each other's variance ( $\mathrm{P}$ - value 0.65 ). HR at 15 mins in FNB and control groups were $77.025 \pm 13.18$ and $99.175 \pm 5.33$ respectively. There was a significant difference in variance between the groups at 15 mins $(\mathrm{P}-$ value <.05). Heart rate during the positioning in FNB and control groups were $75.65 \pm 13.19$ and $101.425 \pm 5.96$ respectively. There was a significant difference in variance between the groups at 15 mins $(\mathrm{P}$ - value < .05). (Figure 2)

Baseline mean arterial pressure (MAP) in FNB group and control groups were $91.9 \pm 6.142$ and $95.1 \pm 7.38$ respectively and were comparable to each other's variance $(\mathrm{P}$ - value 0.302). MAP at 15 mins in FNB and control groups were 79.62 \pm 11.10 and $96.9 \pm 6.27$ respectively. There was a significant difference in variance between the groups at 15 mins ( $\mathrm{P}$ - value $<.05)$. MAP during positioning in FNB and control groups were $78.85 \pm 10.79$ and $99.02 \pm 7.39$ respectively. There was a significant difference in variance between the groups during positioning ( $\mathrm{P}$ - value < .05). (Figure 2)

Baseline VAS in FNB group and control groups were $6 \pm$ 0.751 and $6.075 \pm 0.693$ respectively and were comparable to each other's variance (P - value 0.644). At 15 mins VAS in FNB and control groups were $2.3 \pm 1.042$ and $6.125 \pm 0.607$ respectively. There was a significant difference in variance between the groups at 15 mins ( $\mathrm{P}-$ value $<.05)$. During positioning, VAS in FNB and control groups were $3.025 \pm 0.831$ and $7.2 \pm 0.822$ respectively. There was a significant difference in variance between the groups during positioning $(\mathrm{P}$ - value $<$ 0.005).(Figure 3)

Only 5 patients required intravenous injection fentanyl during positioning and the total amount of injection fentanyl required was $142 \pm 3.21$ microgram $(\mu \mathrm{g})$ in FNB group. In control group, all patients required injection fentanyl and the total amount was $1162 \pm 4.43$ microgram $(\mu \mathrm{g})$ and was statistically very significant $(\mathrm{P}$ - value $<0.005)$. (Table 2 ) 

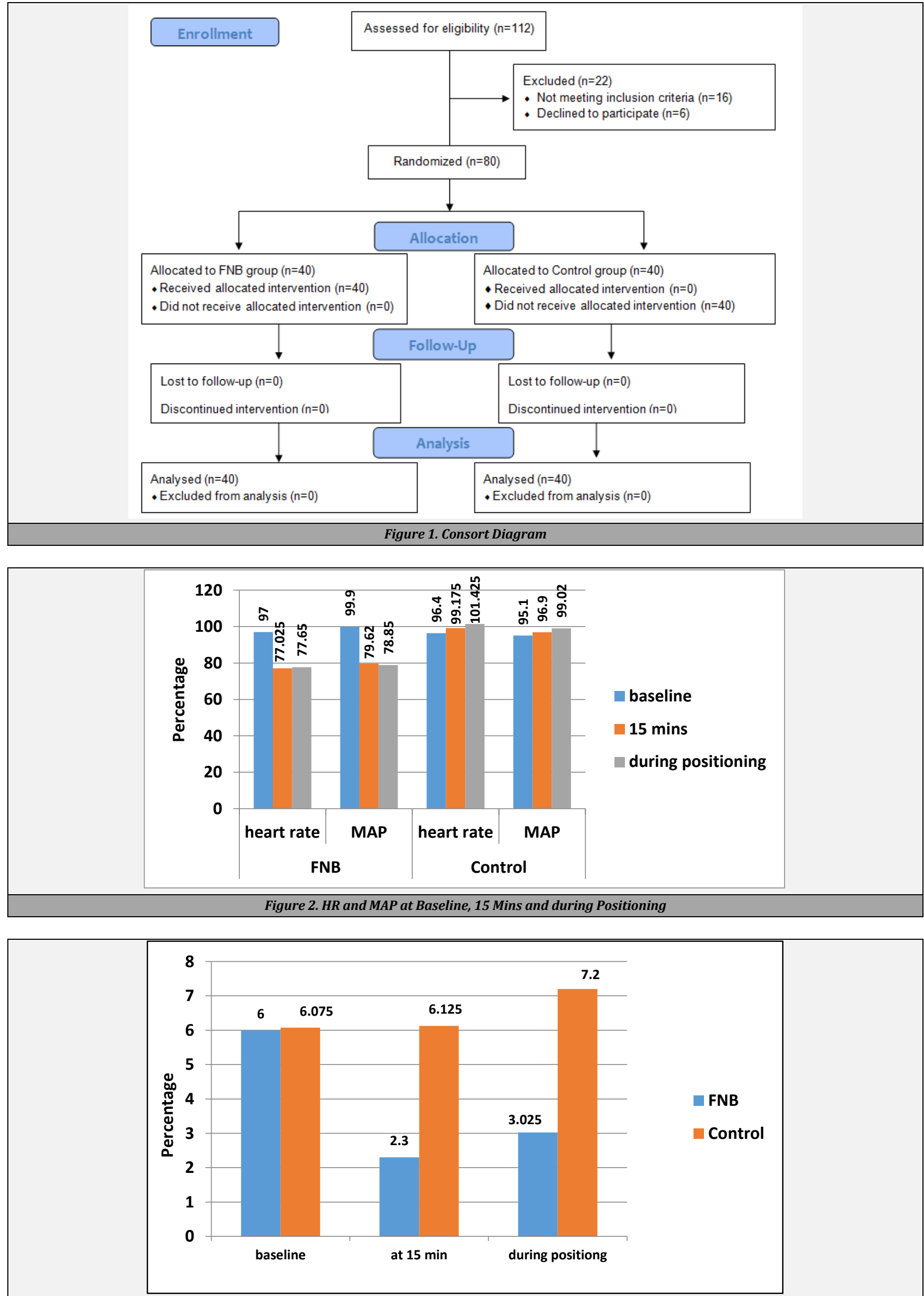

Figure 3. Visual Analogue Scale 


\begin{tabular}{|cccc|}
\hline & $\begin{array}{c}\text { FNB } \\
\text { Mean } \pm \text { SD }\end{array}$ & $\begin{array}{c}\text { Control } \\
\text { Mean } \pm \text { SD }\end{array}$ & P - Value \\
$\begin{array}{c}\text { Total Fentanyl } \\
\text { consumption }(\mu \mathrm{g})\end{array}$ & $142 \pm 3.21$ & $1162 \pm 4.43$ & \\
$\begin{array}{c}\text { Time to perform block } \\
\text { (min) }\end{array}$ & $1.67 \pm .45$ & $3.1 \pm 1.43$ & $<.05$ \\
Likert scale & $3.6 \pm 0.90$ & $1.4 \pm 0.67$ & \\
$\begin{array}{c}\text { Anaesthesiologist } \\
\text { satisfaction }\end{array}$ & yes $32(80 \%)$ & $5(12.5 \%)$ & \\
Table 2. Fentanyl Consumption, Time to Perform Block, \\
Patient and Anaesthesiologists Satisfaction & \\
\hline
\end{tabular}

Time required to perform spinal anaesthesia was $1.67 \pm$ 0.45 mins in FNB group in compared to $3.1 \pm 1.43$ mins in control group. $\mathrm{P}$ - value was $<0.05$. (Table 2 )

32 anaesthesiologists ( $80 \%$ ) expressed satisfaction during spinal anaesthesia while 8 anaesthesiologists were not satisfied during anaesthesia in FNB group. Whereas, in control group only 5 anaesthesiologists $(12.5 \%)$ were satisfied and 35 anaesthesiologists (87.5\%) expressed dissatisfaction during spinal anaesthesia. The variance in satisfaction between the groups was very significant $(\mathrm{P}$ - value $<0.005)$. (Table 2 )

Patient's satisfaction was measured with Likert score. The Likert score of FNB group was $3.6 \pm 0.90$ in compared to $1.4 \pm$ 0.67 in control group which was statistically significant (P value $<0.005$ ). (Table 2 )

\section{DISCUSSION}

A central neuraxial block, preferably spinal anaesthesia is a widely accepted technique for surgeries of the lower limb, especially in elderly patients. ${ }^{5}$ It has so many advantages over general anaesthesia as it is easier and has better respiratory and haemodynamic stability. Early mobilization and less chance of deep vein thrombosis decrease morbidity and mortality. ${ }^{7}$ As it is a very painful condition, at times it becomes difficult to achieve proper positioning during the anaesthetic technique. Different modalities have been used over the years such as injection of opioids, midazolam, ketamine, fascia iliaca block and femoral nerve block to decrease pain during positioning. However, the use of opioids and different sedative agents may cause severe respiratory depression, particularly in co-morbid conditions. ${ }^{13}$ Schiferer A et al. demonstrated significant pain relief preclinically and during transportation with FNB.10 In a systematic review by Yuan - Pin Hsu et al. stated superior analgesia with FNB than injection fentanyl. ${ }^{14}$ Ranjit et al. Raghuraman et al. Zodon et al. Bantie et al. and Sia et al. compared fentanyl with FNB for analgesia of fractured neck of the femur and found adequate and superior pain relief in FNB group. ${ }^{15-19}$ Recently, USG guided femoral nerve block has become more popular and has been used with greater success. In the present study, there was a significant decrease in VAS score in FNB group at 15 mins and during positioning. VAS score during positioning was $3.025 \pm 0.831$ in FNB in comparison to $7.2 \pm 0.822$ in control group. In a study conducted by Ranjit et al. found similar results. ${ }^{15}$ FNB was done with only nerve stimulator with $15 \mathrm{ml} 0.2 \%$ ropivacaine whereas in our study both USG and nerve stimulators were used.

Time to perform spinal anaesthesia was much shorter in FNB than control group in our study which was in accordance with similar study done by Sia et al. ${ }^{19}$ In a study conducted by Iamaroon et al. found pain score of $2.7 \pm 2.6$ at 15 mins which was similar to our study but $6.1 \pm 2.6$ during positioning in comparison to $3.025 \pm 0.831$ in our study. $30 \mathrm{ml}$ solution of 0.3 $\%$ bupivacaine was used in a nerve stimulator guided technique. Time taken to perform spinal anaesthesia was much higher $(7.0 \pm 4.2 \mathrm{mins})$ in comparison to our study (1.67 \pm .4 mins $) .20$

Anaesthesiologist's satisfaction was significantly higher in FNB group in our study which was in line with the various similar studies. ${ }^{11,21-23}$ One important point to be noted in the present study was that 5 points Likert scale was used for patient acceptance which had a significantly high score in FNB group. Likert score was not found in other similar studies.

\section{CONCLUSIONS}

USG guided femoral nerve block provides assured and excellent analgesia with a lower local anaesthetic volume, better patient satisfaction, less time for anaesthesia and satisfactory positioning for central neuraxial block in patients undergoing surgery for a femur fracture.

Data sharing statement provided by the authors is available with the full text of this article at jemds.com.

Financial or other competing interests: None.

Disclosure forms provided by the authors are available with the full text of this article at jemds.com.

\section{REFERENCES}

[1] Bottlang M, Schemitsch CE, Nauth A, et al. Biomechanical concepts for fracture fixation. J Orthop Trauma 2015;29 Suppl 12(0 12):S28-33.

[2] Rathod J, Tijoriwala P. A study of results of fixation of pertrochanteric femur fractures with dynamic hip screw (DHS) \& comparision with past studies. Int J Orthop Sci 2019;5(3):141-7.

[3] Xiong R, Mai Q, Yang C, et al. Intramedullary nailing for femoral shaft fractures in adults. Cochrane Database Syst Rev 2018;2018(2):CD010524.

[4] Sandby-Thomas M, Sullivan G, Hall JE. A national survey into the peri-operative anaesthetic management of patients presenting for surgical correction of a fractured neck of femur. Anaesthesia 2008;63(3):250-8.

[5] Van Waesberghe J, Stevanovic A, Rossaint R, et al. General vs. neuraxial anaesthesia in hip fracture patients: a systematic review and meta-analysis. BMC Anesthesiol 2017;17(1):87.

[6] Gupta PK, Hopkins PM. Regional anaesthesia for all? British Journal of Anaesthesia 2012;109(1):7-9.

[7] Yeung J, Patel V, Champaneria R, et al. Regional versus general anaesthesia in elderly patients undergoing surgery for hip fracture: protocol for a systematic review. Systematic Revew 2016;5(1):1-6.

[8] Stanley I. The anaesthetic management of upper femoral fracture. Current Anaesthesia \& Crticical Care 2005;16(1):23-33.

[9] Wong SSC, Irwin MG. Anaesthesia for fractured neck of femur. Anaesthesia \& Intensive Care Medicine 2018;19(4):175-8. 
[10] Barker R, Schiferer A, Gore C, et al. Femoral nerve blockade administered preclinically for pain relief in severe knee trauma is more feasible and effective than intravenous metamizole: a randomized controlled trial. J Trauma 2008;64(6):1535-8.

[11] Karmarkar AA, Bhatnagar V, Dwivedi D, et al. Evaluation of two different dosages of local anesthetic solution used for ultrasound-guided femoral nerve block for pain relief and positioning for central neuraxial block in patients of fracture neck of the femur. Indian Journal of Pain 2017;31(3):175-9.

[12] Sullivan GM, Artino AR. Analyzing and interpreting data from likert-type scales. J Grad Med Educ 2013;5(4):541-2.

[13] Sandby-Thomas M, Sullivan G, Hall JE. A national survey into the peri-operative anaesthetic management of patients presenting for surgical correction of a fractured neck of femur. Anaesthesia 2008;63(3):250-8.

[14] Hsu YP, Hsu CW, Chu KCW, et al. Efficacy and safety of femoral nerve block for the positioning of femur fracture patients before a spinal block-a systematic review and meta-analysis. PLoS One 2019;14(5):e0216337.

[15] Ranjit S, Pradhan BB. Ultrasound guided femoral nerve block to provide analgesia for positioning patients with femur fracture before subarachnoid block: comparison with intravenous fentanyl. Kathmandu Univ Med J (KUMJ) 2016;14(54):125-9.

[16] Raghuraman MS, Ranjit S. Regarding ultrasound guided femoral nerve block to provide analgesia for positioning patients with femur fracture before subarachnoid block: comparison with intravenous fentanyl in Kathmandu University Medical Journal 2016;54(2):125-9. Kathmandu Univ Med J (KUMJ) 2017;15(57):89-90.
[17] Jadon A, Kedia SK, Dixit S, et al. Comparative evaluation of femoral nerve block and intravenous fentanyl for positioning during spinal anaesthesia in surgery of femur fracture. Indian J Anaesth 2014;58(6):705-8.

[18] Bantie M, Mola S, Girma T, et al. Comparing analgesic effect of intravenous fentanyl, femoral nerve block and fascia iliaca block during spinal anesthesia positioning in elective adult patients undergoing femoral fracture surgery: a randomized controlled trial. J Pain Res 2020;13:3139-46.

[19] Sia S, Pelusio F, Barbagli R, et al. Analgesia before performing a spinal block in the sitting position in patients with femoral shaft fracture: a comparison between femoral nerve block and intravenous fentanyl. Anesth Analg 2004;99(4):1221-4.

[20] Iamaroon A, Raksakietisak M, Halilamien P, et al. Femoral nerve block versus fentanyl: analgesia for positioning patients with fractured femur. Local Reg Anesth 2010;3:21-6.

[21] Zheng X, Tan Y, Gao Y, et al. Comparative efficacy of neuraxial and general anesthesia for hip fracture surgery: a meta-analysis of randomized clinical trials. BMC Anesthesiol 2020;20(1):162.

[22] Madabushi R, Rajappa GC, Thammanna PP, et al. Fascia iliaca block vs intravenous fentanyl as an analgesic technique before positioning for spinal anesthesia in patients undergoing surgery for femur fractures-a randomized trial. J Clin Anesth 2016;35:398-403.

[23] Hartmann FVG, Novaes MRCG, De Carvalho MR. Femoral nerve block versus intravenous fentanyl in adult patients with hip fractures-a systematic review. Braz J Anesthesiol 2017;67(1):67-71. 